\title{
MECHANICAL PROPERTIES OF HIGH NITROGEN 16Cr - 2Ni - Mn - Mo - N STAINLESS STEEL SYNTHESIZED BY MECHANICAL ALLOYING AND SPARK PLASMA SINTERING
}

\author{
Tagir MAKHMUTOV, Nikola RAZUMOV, Anatoliy POPOVICH, Evgeniy GYULIKHANDANOV, \\ Artem KIM, Alexey SHAMSHURIN
}

Peter the Great St. Petersburg Polytechnic University, St. Petersburg, Russian Federation,
mahmutovtagir@mail.ru

https://doi.org/10.37904/metal.2019.844

\begin{abstract}
$16 \mathrm{Cr}-2 \mathrm{Ni}-\mathrm{Mn}-\mathrm{Mo}-\mathrm{xN}$ (wt.\%) stainless steel powders were synthesized by mechanical alloying (MA) of elemental powders and nitrogen-containing ferrochrome ( $\mathrm{FeCrN}$ ) powders alloy. Compaction of resulting powders was carried out using spark plasma sintering (SPS) technology.

The microstructural and phase evolution of the powders at different times of alloying, microstructure, phase composition and mechanical properties after SPS were studied. The X-Ray diffraction (XRD) and Scanning Electron Microscopy (SEM) analysis showed that increasing alloying time up to $30 \mathrm{ks}$ improves chemical homogeneity of the powders and promotes the formation of a-phase solid solution for the sample without nitrogen source and incomplete dissolution of $\mathrm{FeCrN}$ on the a-phase solid solution for the sample with a nitrogen source. The XRD and SEM analysis of sintering samples showed the formation of $\alpha$ and $y$-phase solid solution. Tensile and microhardness tests showed increasing of tensile stress and increasing hardness for the sample with a nitrogen source.
\end{abstract}

Keywords: High nitrogen stainless steels, mechanical properties, mechanical alloying, microstructure, phase evolution

\section{INTRODUCTION}

The widespread application of nitrogen as an alloying element began in the 80's of the last century. Steels produced with high nitrogen content are called high-nitrogen steels (HNS) or nitrogen "superequilibrium" steels. Nitrogen-containing stainless steels are widely used due to the combination of properties such as high strength, corrosion resistance and low cost. Cost reduction is achieved due to the fact that nitrogen is an austenite-forming element; this reduces the nickel amount in steels.

The effect of nitrogen on the structure and properties of ferritic and martensitic chromium stainless steels has been poorly studied [1]. Stainless steels containing about 20 at.\% $(\mathrm{Cr}+\mathrm{Mn})$ made possible to increase the nitrogen solubility limit to around $1 \mathrm{wt} . \%$ (at electro-slag re-melting and a nitrogen pressure of 20-40 MPa in the furnace) [2]. Powder metallurgy methods such as mechanical alloying, gas and plasma atomization, spark plasma sintering make it possible to obtain unique compositions of materials that are difficult to obtain by traditional methods [3-5]. In particular, $\mathrm{Fe} 17 \mathrm{Cr} 4.5 \mathrm{Ni} 6 \mathrm{Mn}$ stainless steels with nitrogen content up to $1.35 \mathrm{wt} . \%$ were obtained by gas atomization and subsequent extrusion [6]. During mechanical alloying of the Fe16Cr11Mn stainless steel in a nitrogen atmosphere [7], an increase in the nitrogen content in steel with an increase in the mechanical alloying time is observed, accompanied by the transition of $\alpha-\mathrm{Fe} \rightarrow \gamma$-Fe, as well as the formation of nitride phases. The maximum content of pure $\mathrm{\gamma}$ - $\mathrm{Fe}$ obtained by mechanical alloying corresponds to $1.372 \mathrm{wt} . \%$ of nitrogen.

This paper presents results of a study of the mechanical properties, microstructure, phase composition of $16 \mathrm{Cr}$ - $2 \mathrm{Ni}-\mathrm{Mn}-\mathrm{Mo}-\mathrm{xN}$ stainless steel obtained by mechanical alloying (MA) followed by spark plasma sintering (SPS). 


\section{MATERIALS AND METHODS}

A mixture of pure metal powders was used as a material for the study in the following ratio: $\mathrm{Fe}-80 \mathrm{wt} . \%, \mathrm{Cr}-$ 16 wt. \%, Ni-2 wt.\%, Mo-1 wt.\%, Mn-1 wt.\%, FeCrN powders ( $\mathrm{Cr}-81$ wt.\%, N - 19 wt.\%) was used to produce $\mathrm{HNS}$, in an amount of $50 \%$ by weight in terms of pure chromium.

Mechanical alloying was performed on a laboratory attritor with the following parameters: shaft rotation speed - $600 \mathrm{rpm}$, volume of the grinding chamber - 15 liters, the diameter of the grinding balls $-7-10 \mathrm{~mm}$, average diameter of the balls $-8.6 \mathrm{~mm}$, mass of ball $-20 \mathrm{~kg}$, the weight ratio of feed powder to the ball mass $-1: 20$, grinding time 5-30 ks. Alloying was carried out an argon atmosphere to prevent oxidation of the material. The obtained powder was sieved with a mesh size: $45,71,125 \mu \mathrm{m}$.

Sintering of the obtained powders was carried out on the equipment for plasma spark sintering FCT System HPD25 with the following parameters: sintering temperature $-100{ }^{\circ} \mathrm{C}$, pressure $-48 \mathrm{MPa}$, sintering time -5 minutes, pulse duration $-10 \mathrm{~ms}$, pause duration $-2 \mathrm{~ms}$, heating rate $-100^{\circ} \mathrm{C} / \mathrm{min}$, atmosphere -vacuum, mold material - graphite.

The phase composition was investigated by XRD (X-Ray diffraction analysis), using Bruker D8 ADVANCE (Germany) diffractometer in Cu Ka-rays $(\lambda=0.15418 \mathrm{~nm}, U=40 \mathrm{kV}, \mathrm{I}=40 \mathrm{~mA})$. The processing of the obtained diffraction data was carried out according to the Rietveld method using the Diffrac Plus Topas program.

The morphology of the obtained powders, the structure of the sintered samples and the distribution of elements were studied using a scanning electron microscope Mira 3 Tescan with EDX for energy-dispersive x-ray spectroscopy.

The microhardness was measured on Buehler microhardness tester with a load of 300 grams. Measurements were carried out on ground and polished specimens along a section parallel to the height of the cylindrical specimen. Measurements were carried out in a straight line with a step of 50-250 $\mu \mathrm{m}$ from the upper edge of the sample to the centre.

Tensile tests were performed on flat specimens using the Zwick/Roell Z100 mechanical test equipment. Measurements of the deformation were carried out on the traverse of the testing machine.

\section{RESULTS AND DISCUSSION}

Figure 1 shows the SEM images of $16 \mathrm{Cr}-2 \mathrm{Ni}-\mathrm{Mn}-\mathrm{Mo}$ (a) and 16Cr-2Ni-Mn-Mo-N (b) powder particles sections obtained by MA with the milling time of $30 \mathrm{ks}$. The powders obtained by MA have irregular particles' shape typical for milling processes. In the cross-section of the MA powder (without nitrogen content) treated for 30 $\mathrm{ks}$, elongated inclusions of molybdenum up to $10 \mu \mathrm{m}$ in length are observed. The MA powder of HNS has elongated molybdenum inclusions, as well as undissolved dark grey inclusions of $\mathrm{FeCrN}$.

The change of the phase composition during the mechanical alloying of stainless steel is shown in Figure 2. Iron and chromium have a common space group and similar lattice parameters, on the XRD pattern of the raw powder their peaks partially overlap and the asymmetry of the peaks is visible. The asymmetry is most pronounced for the raw powder, but with increasing MA time, the asymmetry of the peaks decreases. That indicates the dissolution of chromium in iron and formation of a solid solution. The decrease in intensity of molybdenum peak indicates the dissolution of molybdenum in iron, however, for complete dissolution, it is necessary to increase the processing time or the energy intensity of the alloying process. Nitrogen in the raw powder is in the form of $\mathrm{Cr}_{2} \mathrm{~N}$ and $\mathrm{CrN}$ compounds. There is a significant decrease in the intensity of the nitride components after $30 \mathrm{ks}$ of alloying however, the presence of inclusions of nitrides in the SEM images indicates that the nitrogen is not completely dissolved. 

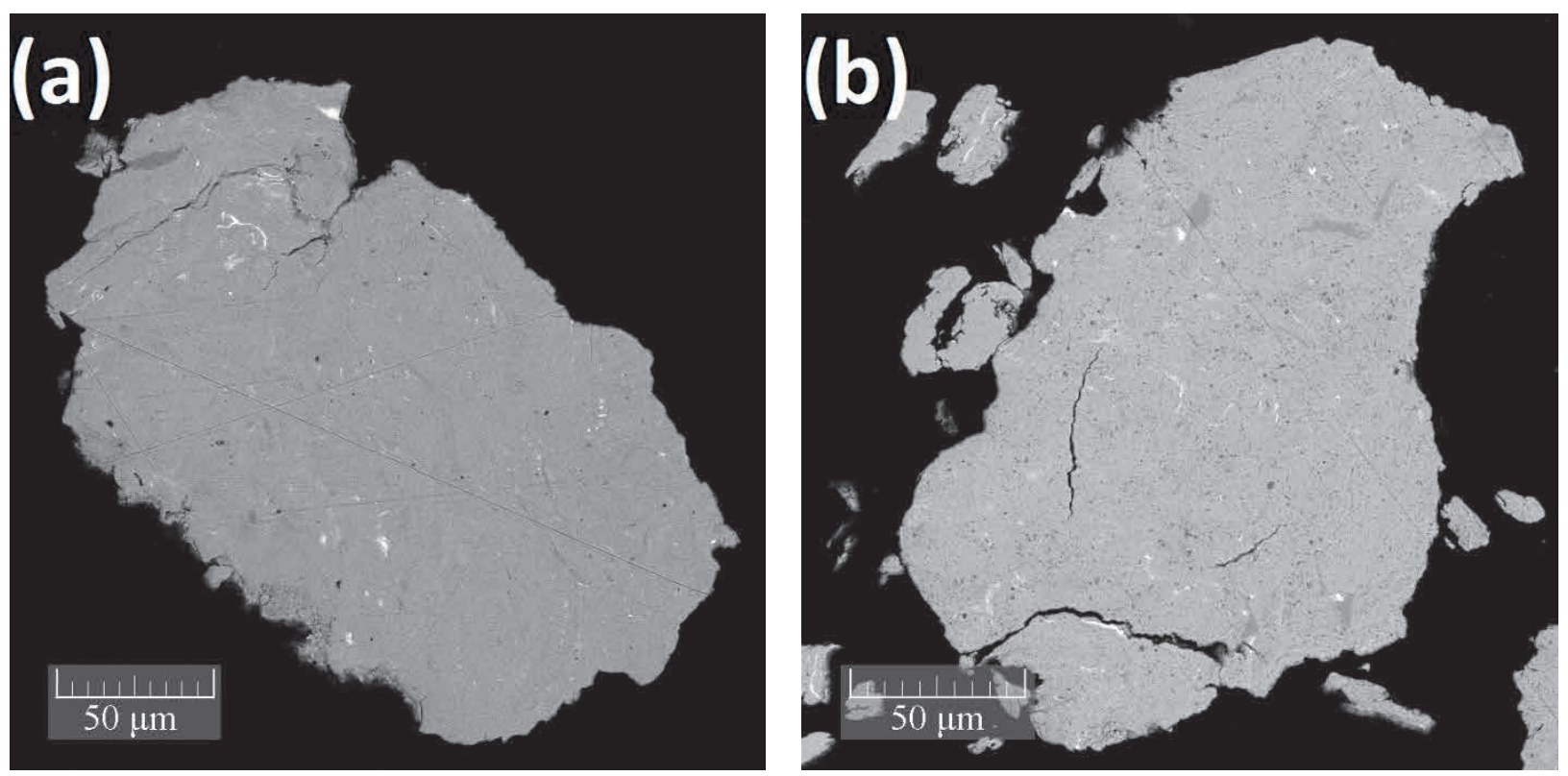

Figure 1 SEM images of 16Cr-2Ni-Mn-Mo (a) and 16Cr-2Ni-Mn-Mo-N (b) powder particles sections obtained by MA with the milling time of $30 \mathrm{ks}$
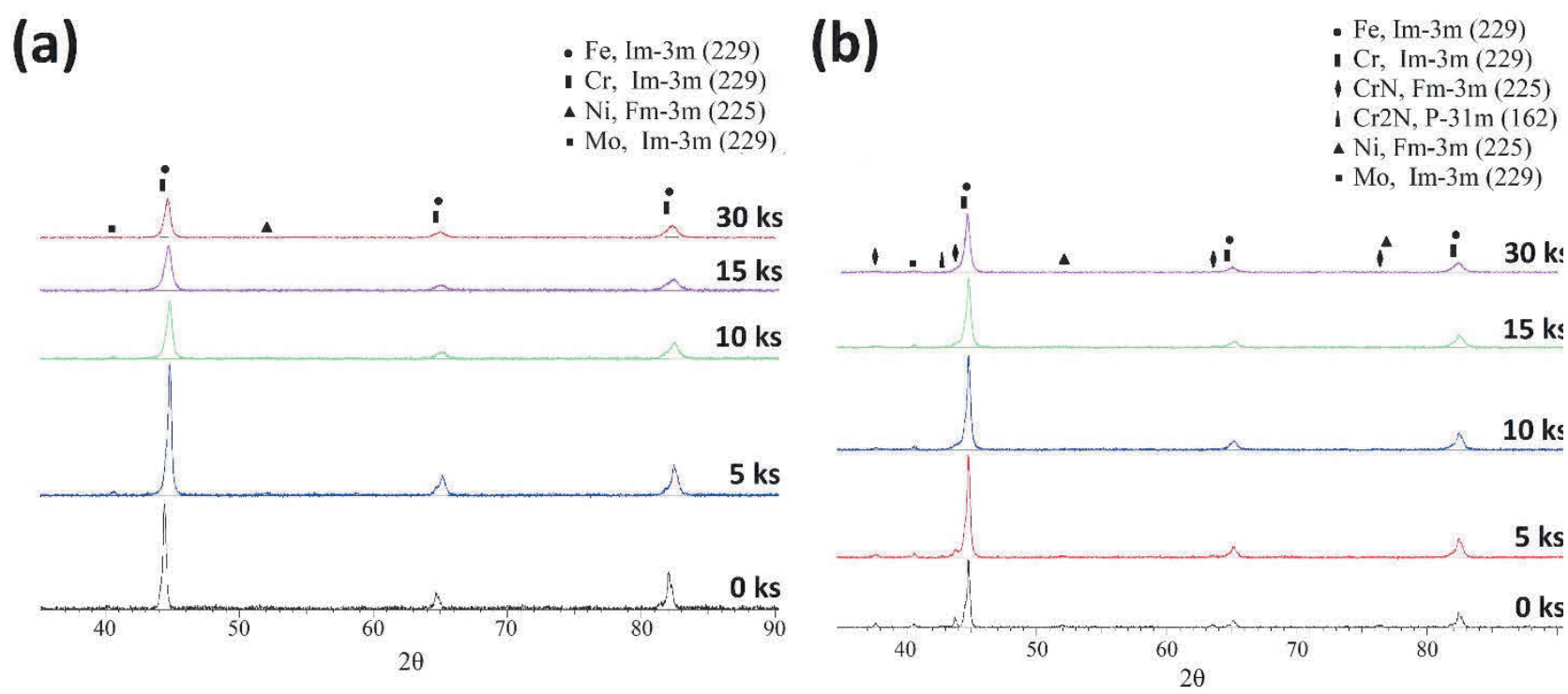

Figure 2 XRD results of 16Cr-2Ni-Mn-Mo (a) and 16Cr-2Ni-Mn-Mo-N (b) powders obtained by MA at different milling times

SEM images of the sample obtained from MA powders by sintering using SPS are shown in Figure 3. The image (a) characterizes the sample obtained without nitrogen content. There are visible white areas on the sample surface corresponding to undissolved molybdenum. The sintered sample 16Cr-2Ni-Mn-Mo-N (b) contains inclusions in the form of undissolved $\mathrm{Cr}_{2} \mathrm{~N}$ (dark grey areas).

Figure 4 shows the XRD results of the sintered sample. The phase composition of both samples is represented by two phases - $\alpha-\mathrm{Fe}$ and $\mathrm{y}-\mathrm{Fe}$. The phase content for the $16 \mathrm{Cr}-2 \mathrm{Ni}-\mathrm{Mn}-\mathrm{Mo}$ (2) sample is $\alpha-\mathrm{Fe} 93.5 \% / \mathrm{Y}-\mathrm{Fe}$ $6.5 \%$, for the $16 \mathrm{Cr}-2 \mathrm{Ni}-\mathrm{Mn}-\mathrm{Mo}-\mathrm{N}$ (1) sample is $\alpha-\mathrm{Fe} 77.5 \% / \mathrm{Y}-\mathrm{Fe} 22.5 \%$. The increase of $\mathrm{y}$-Fe phase is associated with the dissolution of nitrogen and $\alpha-\mathrm{Fe} \rightarrow \mathrm{y}-\mathrm{Fe}$ transition. The broadening of the peaks is due to the presence of micro-stresses caused by the formation of a solid solution. 

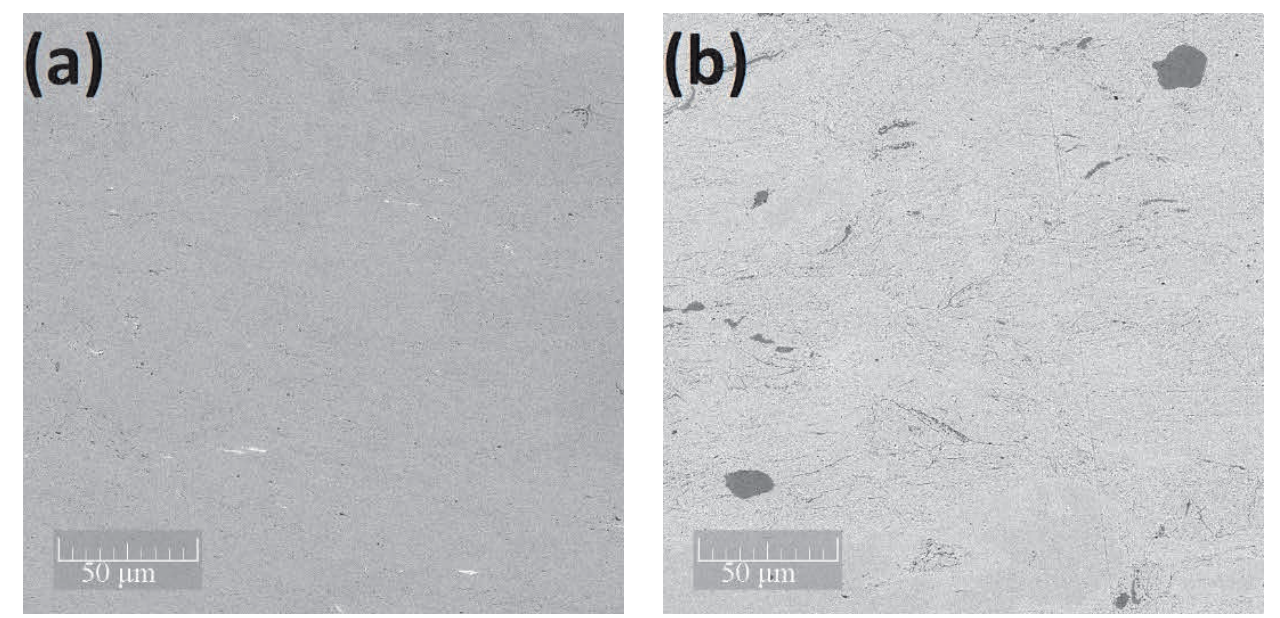

Figure 3 Microstructure of 16Cr-2Ni-Mn-Mo (a) and 16Cr-2Ni-Mn-Mo-N (b) samples after sintering

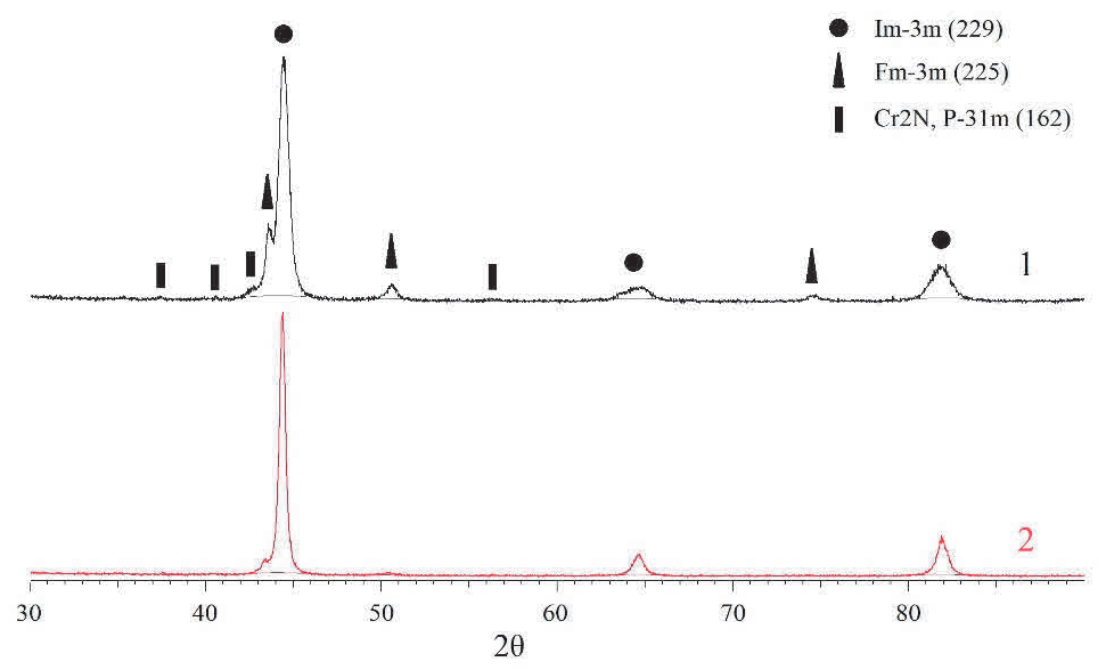

Figure 4 XRD results of the sintered sample

(a)

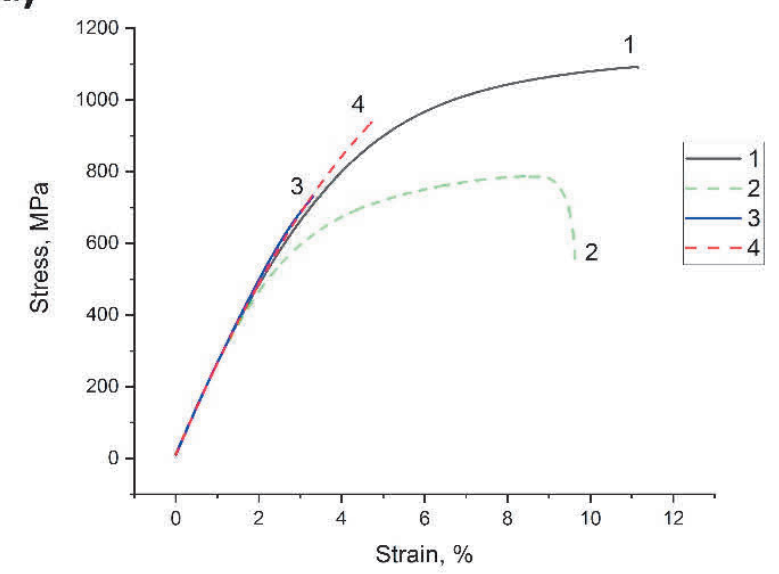

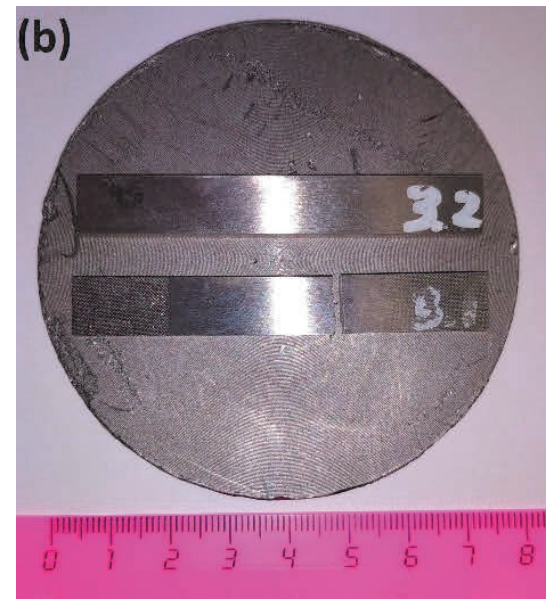

Figure 5 Stress-strain curve of samples

(a), cylindrical powder compact and specimens before and after the tensile test (b) 
Figure 5 shows the stress-strain curve (a), cylindrical powder compact and specimens before and after the tensile test (b) of samples obtained from mechanically alloyed powders by SPS. Curve (1) characterizes the sample $16 \mathrm{Cr}-2 \mathrm{Ni}-\mathrm{Mn}-\mathrm{Mo}$ after SPS, curve (2) 16Cr-2Ni-Mn-Mo after SPS and tempering at $680^{\circ} \mathrm{C}$, curve (3) $16 \mathrm{Cr}-2 \mathrm{Ni}-\mathrm{Mn}-\mathrm{Mo}-\mathrm{N}$ Mo after SPS, curve (4) 16Cr-2Ni-Mn-Mo-N-Mo after SPS and tempering at $680{ }^{\circ} \mathrm{C}$. Table 1 is dedicated to the value of proof stress, tensile strength and elongation of the sample. The measurement of the strain value along the traverse of the testing machine differs from the values measured manually, due to the effect of the forces on the bolt joints and screws of the traverse. The test results show a decrease in the strength of high-nitrogen steel compared to nitrogen-free steel when testing specimens sintered in SPS. However, testing samples tempered at $680^{\circ} \mathrm{C}$ showed an increase in strength of the highnitrogen steel.

Table 1 Results of tensile tests.

\begin{tabular}{|c|c|c|c|c|}
\hline Sample № & Materials & Proof stress, MPa & $\begin{array}{c}\text { Tensile strength, } \\
\mathbf{M P a}\end{array}$ & $\begin{array}{c}\text { Elongation } \\
\text { (manually } \\
\text { measured), } \%\end{array}$ \\
\hline 1 & $16 \mathrm{Cr}-2 \mathrm{Ni}-\mathrm{Mn}-\mathrm{Mo}$ & 438.6 & 1092.2 & 4.0 \\
\hline 2 & $16 \mathrm{Cr}-2 \mathrm{Ni}-\mathrm{Mn}-\mathrm{Mo} \mathrm{HT}$ & 365.8 & 786.6 & 1.8 \\
\hline 3 & $16 \mathrm{Cr}-2 \mathrm{Ni}-\mathrm{Mn}-\mathrm{Mo}-\mathrm{N}$ & 516.8 & 730.9 & 2.8 \\
\hline 4 & $16 \mathrm{Cr}-2 \mathrm{Ni}-\mathrm{Mn}-\mathrm{Mo}-\mathrm{N} \mathrm{HT}$ & 468.1 & 938.2 & 2.0 \\
\hline
\end{tabular}

The micro-hardness values of the samples over the cross-section are not homogeneous (Figure 6). The difference in hardness at the edges of the samples may be due to carburization of the surface layer. The average hardness of high-nitrogen steel is higher than that of nitrogen-free steel by $60-70 \%$. The increase in hardness can be associated with stresses in the crystal lattice, which have arisen during the formation of a solid solution, as well as with nitride inclusions in high-nitrogen steel.

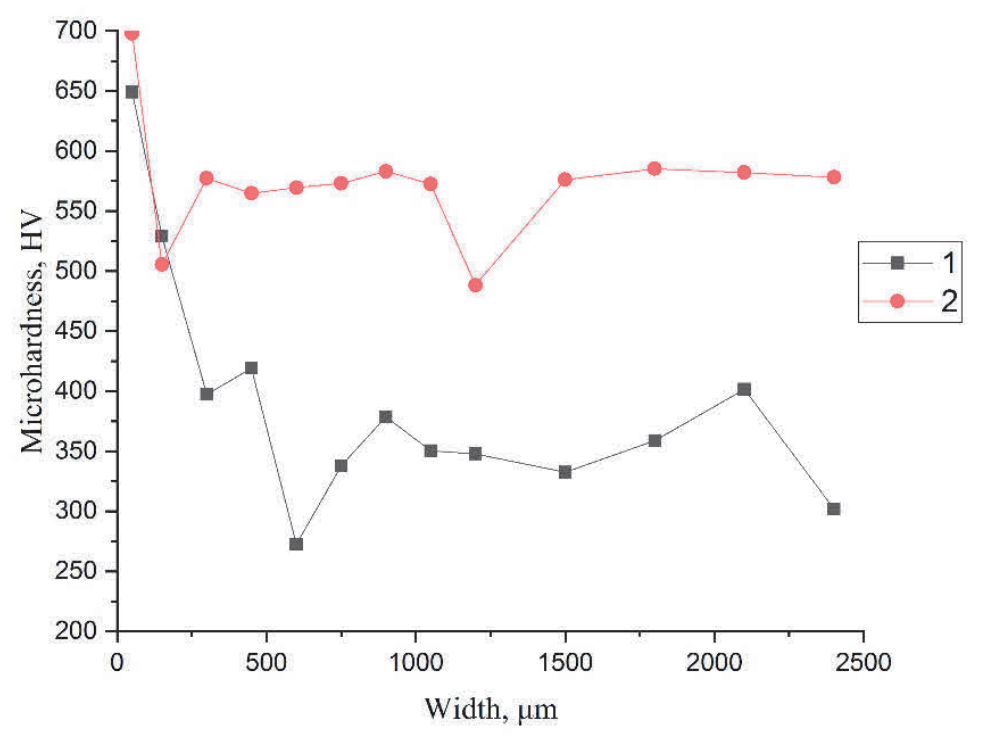

Figure 6 Microhardness of samples

\section{CONCLUSION}

In the present work, $16 \mathrm{Cr}-2 \mathrm{Ni}-\mathrm{Mn}$ - Mo - xN (wt.\%) stainless steel powders were synthesized by mechanical alloying. Compaction of resulting powders was carried out using spark plasma sintering. 
Increasing alloying time up to $30 \mathrm{ks}$ improves chemical homogeneity of the powders and promotes the formation of $\alpha$-phase solid solution for the sample without nitrogen source and incomplete dissolution of FeCrN on the $\alpha$-phase solid solution for the sample with a nitrogen source. Sintered samples have the following phase

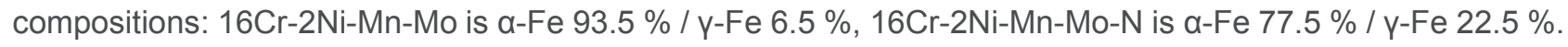

Doping with nitrogen increased the hardness of stainless steel by $60-70 \%$. The tensile strength of highnitrogen steel increased after tempering at $680^{\circ} \mathrm{C}$ (before $730.9 \mathrm{MPa}$, after 938.2), and the tensile strength of nitrogen-free steel decreased after heat treatment (before 1092.2 MPa, after 786.6).

\section{ACKNOWLEDGEMENTS}

This research was supported by Russian Science Foundation grant (project № 18-73-00191).

\section{REFERENCES}

[1] BANNYKH, O. A., BLINOV, V. M. and KOSTINA, V. M. Structure and properties of low-alloy high-nitrogen martensitic steels. Metal Science and Heat Treatment. 2003. vol. 45, no. 1 - 2, pp. 43-48.

[2] FOCT J. Unexplored Possibilities of Nitrogen Alloying of Steel. In: Advanced Steels., Berlin, Heidelberg: Springer, 2011, pp. 363-366.

[3] BOLDYREV, V. V. Mechanochemistry and Mechanical Activation of Solids. Russian Chemical Reviews. 2002. vol. 75 , no. 3, pp. 203-206.

[4] MUNIR, Z.A., ANSELMI-TAMBURINI, U. and OHYANAGI, A.. The effect of electric field and pressure on the synthesis and consolidation of materials: A review of the spark plasma sintering method. Journal of Materials Science. 2006. vol. 41, no. 3, pp 763-777.

[5] RAZUMOV, N. G., POPOVICH, A. A. and WANG, Q. Thermal Plasma Spheroidization of High-Nitrogen Stainless Steel Powder Alloys Synthesized by Mechanical Alloying. Metals and Materials International. 2018. vol. 24, no. 2, pp 363-370.

[6] SIMMONS, J. W, KEMP, W. E. and DUNNING, J. S. The P/M Processing of High-Nitrogen Stainless Steels. Journal of Materials Science. 1996. vol. 48, no. 4. pp 20-23.

[7] CISNEROS, M. M. Processing of Nanostructured High Nitrogen Stainless Steel by Mechanical Alloying. Metallurgical and Materials Transactions. 2005. vol. 36A, no. 5, pp. 1299-1316. 